\title{
Activity pattern and fat accumulation strategy of the Natterer's bat (Vespertilionidae, Chiroptera) swarming population indicate the exact time of male mating effort
}

\author{
Joanna Kohyt ${ }^{1}$ - Agata Rozik ${ }^{2}$ - Katarzyna Kozakiewicz ${ }^{3}$ - Andrea Pereswiet-Soltan ${ }^{3,4}$. \\ Wojciech J. Gubala ${ }^{5}$
}

Received: 15 August 2015 / Accepted: 4 July 2016/Published online: 11 July 2016

(C) The Author(s) 2016. This article is published with open access at Springerlink.com

\begin{abstract}
Studies concerning bat autumn swarming behavior suggest that the main purpose of this phenomenon is mating. However, the process of fat accumulation is crucial for surviving winter, and it seems to be in clear conflict with a need to strive for the opportunity to mate prior to hibernation. Investment in one activity limits the other one creating a trade-off between them. The aim of our study was to describe the activity pattern of each sex-age group (adult males, adult females, subadults) of the Natterer's bat during swarming period and to investigate the fat accumulation process of adult males in the context of their reproductive strategy. Bats were captured by mist nets at the swarming site fortnightly from the early August until the late November. The age, sex, reproductive status, and body condition index (mass to forearm ratio, BCI) were recorded. The activity peak of both sexes, adults, and subadults was observed in the late September. That time in season, $\mathrm{BCI}$ of adult males was the lowest, and there was no
\end{abstract}

Communicated by: Karol Zub

Joanna Kohyt

joanna.kohyt@us.edu.pl

1 Department of Ecology, Faculty of Biology and Environmental Protection, University of Silesia, Bankowa 9,

40-007 Katowice, Poland

2 Institute of Environmental Sciences, Jagiellonian University, Gronostajowa 7, 30-387 Kraków, Poland

3 Institute of Systematics and Evolution of Animals, Polish Academy of Sciences, Sławkowska 17, 31-016 Kraków, Poland

4 Club Speleologico Proteo, Viale Riviera Berica, 631, 36100 Vicenza, Italy

5 Stowarzyszenie Ochrony Jaskiń “Grupa Malinka”, Fiedorowska 66, 43-460 Wisła, Poland correlation between the hour of an adult male capture and its BCI value within one night $\left(r_{\mathrm{s}}=0.23 ; p=0.157\right)$. Such correlation was observed later in the season (early October: $r_{\mathrm{s}}=0.44$; $p=0.020$; late October: $r_{\mathrm{s}}=0.48 ; p=0.002$ ). A negative correlation between adult males' BCI and proportion of adult females was found $(r=0.44 ; p=0.000)$. We conclude that the activity peak of females is likely to be responsible for the effort of the mating behavior of the males, which is reflected by their low condition index. We suggest that the gleaning foraging strategy of Natterer's bat allows the males to postpone their fat accumulation until just before hibernation.

Keywords Seasonal activity patterns - Sex ratio - Male BCI · Foraging strategy · Mating · Trade-off · Myotis nattereri

\section{Introduction}

The term "swarming," with regard to the temperate zone bats, was described as an increase in bat activity in front of the hibernacula, before the hibernation period. It appeared in the $1960 \mathrm{~s}$ and referred to the behavior of Myotis lucifugus (North America) (Fenton 1969). At that time, the explanation for this activity was presented as a combination of three main hypotheses: mating, familiarizing juveniles with accessible wintering sites, and the final arrival of bats to the hibernacula. To date, results of genetic surveys suggest that mating is the main purpose of swarming (Kerth et al. 2003; Furmankiewicz and Altringham 2007; Bogdanowicz et al. 2012). It is suggested that the Natterer's bat is one of several European species mating during swarming (Rivers et al. 2005). This species exhibits similar behavior to other swarming bats performing chasing flights with social calls (Trappmann 1997; Rivers et al. 2005). Because swarming activity of most temperate bats occurs in autumn, it is in strong 
conflict with the necessity of fat accumulation for hibernation. It means that a bat has to compromise between spending time and energy on both activities, because an individual success (survival and reproduction) depends on the effect of proper investment. Males usually outnumber females during the entire swarming season (Rivers et al. 2006; Gottfried 2009; Piksa et al. 2011). This is interpreted as males spend more time at swarming sites than females to increase the number of copulations, which enhances their reproductive success (Rivers et al. 2006). Temperate bat species vary in their foraging techniques and often use different food resources. Feeding strategy may influence bat behavior, such as emergence time, night activity peaks, and commuting to feeding grounds, especially when weather conditions deteriorate. Species efficiency of food resources exploitation may be crucial in fat accumulation strategy before hibernation. Bat species differ in timing of their activity peaks in the swarming season, which lasts from the middle of summer to the late autumn (Furmankiewicz and Górniak 2002; Parsons et al. 2003; Piksa et al. 2011). An explanation of the late activity peak of the Natterer's bat proposed by Parsons et al. (2003) was its gleaning strategy, which makes foraging activity independent of low air temperature.

The Natterer's bat has not yet been studied in the context of the autumn fat accumulation strategy, especially on the background of energy-consuming swarming behavior. The aim of this study was to describe the activity pattern of sex-age groups of this species and to investigate the autumn fat accumulation strategy of males. As the consequence of the tradeoff between reproduction success in mating and survival during hibernation, we expect:

1. prolonged activity of adult males in season in comparison to subadults and adult females

2. negative relation between the BCI value of adult males and the proportion of adult females

3. late fat stores buildup of adult Natterer's bat males relating to the species foraging strategy

\section{Material and methods}

\section{Study area}

The study was carried out in the Ciężkowickie Foothills, Skamieniałe Miasto Reserve in southern Poland (N 49 46' 39"; E $20^{\circ} 57^{\prime} 56^{\prime \prime}$ ) (Fig. 1). This area is a mosaic of different habitats such as cropland, grassland, wasteland, buildings, rivers, and patches of forest. The reserve was primarily created to protect sandstone rock formations and is mostly covered by a deciduous forest with well-developed undergrowth. Altogether 38 caves have been described in the Ciężkowickie Foothills to date (Klassek and Mleczek 2014), thirteen of them are located within the Skamieniałe Miasto Reserve. Three largest caves situated on the same slope of the gorge were selected for research: Skamieniała Cave (20-m length, 9-m denivelation), Pajęcza Cave (9-m length) and Krótka Cave (10-m length) (Mleczek 1997). Other caves in the reserve are only small niches in the rock formations (Fig. 1).

\section{Material and methods}

The mist netting was carried out fortnightly from the beginning of August until the end of November in 2009 and 2010. Bats were caught using mist nets (Ecotone, Poland) in front of three caves: Skamieniała, Pajęcza, and Krótka (mist nets partially covered the entrances). The catches were carried out on nearly the same dates of the two seasons. They began at dusk and lasted from 6 to $10 \mathrm{~h}$, until bat activity ceased. The species, sex, and reproductive status of the captured bats were identified in order to determine the swarming activity pattern of each sex-age group of the Natterer's bat (adult males, adult females, subadults). The age was determined by the degree of the ossification of the epiphyseal joints in the finger bone bases and by other auxiliary traits like pelage color or degree of tooth wear (Racey 1974; Anthony 1988; Schick et al. 2003; Haarsma 2008). If there was any doubt, the bat was classified as subadult. Measurements of right forearm length [mm] and body mass [g] were taken and the time of capture was noted to estimate the condition of captured bats both for the time in season and night. A non-toxic color alcohol marker was applied on a bat's back between blades to avoid double measurements of the same individual. The bats were released at the site of capture immediately after the measurements were completed.

\section{Statistical analysis}

The data from both years were pooled to increase the sample size. The body condition index (BCI) was applied as the estimator of a bat's condition, which is defined as body mass to forearm ratio [g/mm] (Speakman and Racey 1986). One-way ANOVA was performed to test the differences of the mean values of BCI of the Natterer's bat adult males between the nights in season. The Box-Cox transformation was applied to normalize the data distribution. The homogeneity of variance was confirmed by means of Levene's test. A post hoc Tukey's test for unequal numbers for assessing the significance of any differences between the catches was performed. This analysis was conducted to check the changes in BCI between nights in the swarming season to estimate when the fat reserve buildup for adult males starts. The relationship between bats' BCI and the subsequent hours ( $1 \mathrm{~h}$ interval) of the night was tested using Spearman's rank correlation. For these analyses the sunset hour was the zero hour. Three consecutive nights on which there were sufficient numbers of adult males (starting from the 
Fig. 1 Study area, Skamieniałe Miasto Reserve, southern Poland, with forest cover, location of sandstone formations, caves and mist-netting sites



activity peak night) were analyzed, while only the activity peak night was analyzed for adult females and subadults. These analyses were conducted to test if the nights of the highest activity are spent on feeding, which would be seen in positive correlation between bats' $\mathrm{BCI}$ and the consecutive hours of the night. The relationship between adult males' BCI and proportion of females caught per night was analyzed using Pearson's correlation to test if the higher proportion of females affects negatively the males' BCI values. Data analyses were performed using STATISTICA 10.0.

\section{Results}

\section{The Natterer's bat swarming population activity and structure (sex-age groups)}

The Natterer's bat was the dominant species within the swarming season $(55.1 \%$ of the entire season, $77.3 \%$ at the peak of the swarming activity). Because of absence of this species in the beginning of August, only 14 nights were analyzed. Within all sex-age groups, during both years, the adult males predominated (145 males, 29 females, 32 subadults altogether) (Table 1). The adult male to female ratio changed during the season, but males always outnumbered females: for the whole period studied it was ca. 5:1 (83.3\% for adults only, $81.5 \%$ including subadults). Sexually active adult males (swollen cauda epididymides) constituted $88.6 \%$ of all of the captured adult males. Adult males and subadults were present throughout the whole season while adult females were not. The peak of activity of adult females and subadults overlapped. It occurred in late September and was also the species activity peak. Adult males had relatively high level of activity from late September to late October (Fig. 2a). Adult males and females showed different activity patterns which were constant in both years (Fig. 2b).

\section{The body condition index (BCI) of the Natterer's bat swarming population}

One-way ANOVA followed by Tukey's post hoc test revealed differences between individual nights regarding adult males' $\mathrm{BCI}$ $\left(F_{(6,130)}=17.80, p=0.000\right)$. The lowest mean BCI value of the adult males was observed at the time of the peak activity of the adult females. Later in season, the BCI values of the males increased (Fig. 2c). At the peak of swarming activity (late September), there were no changes in BCI during the night (adult males: $r_{\mathrm{s}}=0.23, p=0.157$; adult females: $r_{\mathrm{s}}=0.32, p=0.177$; subadults: $\left.r_{\mathrm{s}}=0.36, p=0.193\right)$. In contrast, positive and significant changes in males' BCI were observed during the next two 
Table 1 Total number of the Natterer's bats captured during the autumn swarming season in Skamieniałe Miasto Reserve (fortnightly, a 2-year study)

\begin{tabular}{lllllllll}
\hline & Aug_1 & Aug_2 & Sept_1 & Sept_2 & Oct_1 & Oct_2 & Nov_1 & Nov_2 \\
\hline Adult males & 0 & 10 & 4 & 38 & 29 & 40 & 18 & 6 \\
Adult females & 0 & 3 & 0 & 18 & 6 & 0 & 2 & 0 \\
Subadults & 0 & 2 & 1 & 17 & 8 & 1 & 2 & 1 \\
Total & 0 & 15 & 5 & 73 & 43 & 41 & 22 & 7 \\
\hline
\end{tabular}

nights (not enough data to analyze adult females and subadults). In early October, the correlation was moderate $\left(r_{\mathrm{s}}=0.44\right.$,
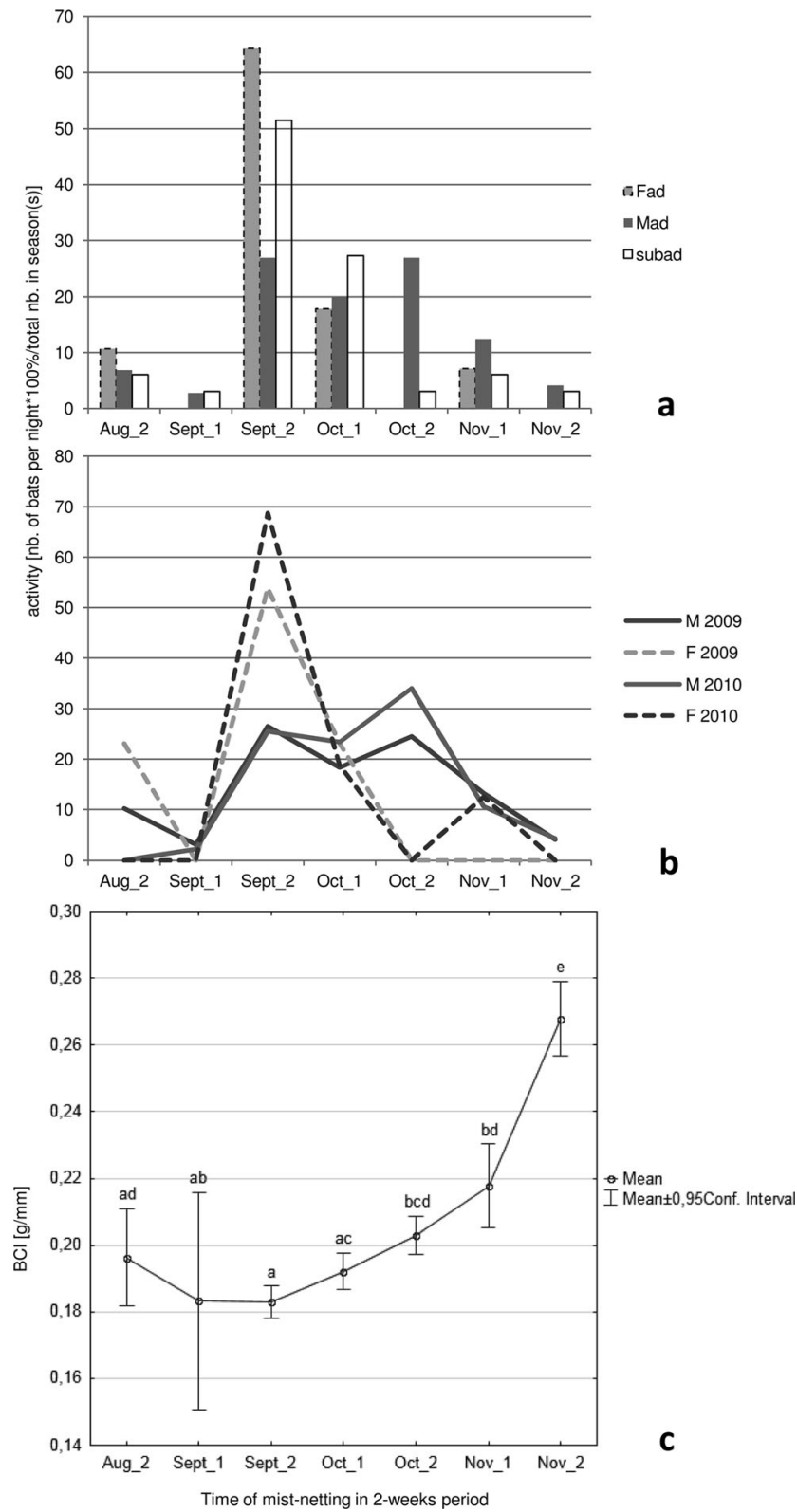

Fig. 2 The Natterer's bat activity presented as \% calculated separately for each sex-age group. a Adult males, females and subadults fraction of the entire seasonal activity (two years together) in 2-week periods of time. b Adult males and females fractions of the entire seasonal activity (each year separately). c Adult males BCI (body condition index) changes, post hoc Tukey's statistical differences at $p<0.05$ presented as different letters $p=0.020)$, and became stronger in late October $\left(r_{\mathrm{s}}=0.48\right.$, $p=0.002)$. Negative and significant correlation of adult males BCI value and proportion of females caught per night was observed during season $(r=-0.44, p=0.000)$.

\section{Discussion}

\section{The swarming activity patterns of three sex-age groups} of the Natterer's bat

The swarming activity pattern of the Natterer's bat in the Skamieniałe Miasto Reserve, with relatively late maximum (late September), resembles that reported from a bat hibernacula in Poland (Furmankiewicz and Górniak 2002; Piksa 2008; Piksa et al. 2011), but also in Latvia (Šuba et al. 2008) and UK (Parsons et al. 2003; Rivers et al. 2006; Glover and Altringham 2008). Adult individuals prevailed over young bats as in other studies (Furmankiewicz and Górniak 2002; Glover and Altringham 2008; Piksa 2008; Gottfried 2009). The high male ratio: $81.5 \%$ (subadults included) and their reproductive status ( $88.6 \%$ sexually active) is also comparable with other swarming sites of the Natterer's bat in Poland and UK (Furmankiewicz and Górniak 2002; Rivers et al. 2006; Glover and Altringham 2008).

Our studies confirmed some earlier observations on sexage group activity patterns, e.g., the proportion of females (adults and subadults pooled) increased in late September (at the species activity peak) and, in contrast to males (adults and subadults), females visited the swarming site less frequently and relatively shorter in season than males (Rivers et al. 2006; Glover and Altringham 2008). The shorter presence of adult females in comparison to adult males is consistent with the different trade-off between mating and foraging for these sexage groups. Males do not contribute to raising their offspring. Therefore, they should spend more time and energy at swarming sites than females to increase the number of copulations (inseminated females), which increases their reproductive success (Rivers et al. 2006). In contrast, reproductive success of females depends on saving as much fat reserves as possible to the end of hibernation in order to enter gestation in good body condition (Kunz et al. 1998; Jonasson and Willis 2011). In consequence, for females, it is profitable to reduce the number of copulations and energy spent on mating. 
Studies of the Natterer's bat in the Skamieniałe Miasto Reserve revealed that the activity peak of adult females overlaps with activity peak of subadults, as it has been earlier observed for two other swarming species Myotis mystacinus and Myotis daubentonii (Piksa 2008; Šuba et al. 2008). Our observation corroborates the hypothesis that subadult bats come to swarming sites following mothers or female relatives from the same nursery colony (Furmankiewicz 2008; Piksa 2008). For the youngs of the year, it is crucial to gather as much information about the home area as possible, e.g., to know where their conspecifics gather for mating and/or hibernation. However, because most of temperate insectivorous bats are reproductively active in the second year of life, in the case of subadults, reproduction versus fat accumulation trade-off in autumn is highly skewed towards completing fat reserve storage for winter (Kunz et al. 1998; Encarnação et al. 2006). Especially that for young, inexperienced bats, foraging probably requires greater effort than for adults.

Comparing the three mentioned sex-age groups the tradeoff between reproduction and autumn fat accumulation generates the greatest conflict for adult males. One may expect that males should monitor the swarming site constantly to increase the probability of mating and at the same time should keep on foraging to build up the fat reserves for hibernation. To check whether this hypothesis is valid for the Natterer's bat males, we followed BCI changes in this group.

\section{Condition of adult males of the Natterer's bat in relation to presence of adult females}

Our data allowed to analyze and therefore to discuss in detail the BCI changes within the entire swarming season for adult males only. In case of females, the BCI changes were analyzed only at their peak of activity (late September). The body condition of adult males and females during the maximum activity night did not change in time, which means that both sexes did not forage intensely then. Furthermore, the males' BCI value was the lowest at the peak of adult females' activity and was negatively correlated with the proportion of adult females in the entire swarming season. Contrary, in consecutive hours of the nights of no or low activity of females (early October or late October), the males' BCI value was slightly growing. It suggests that adult males in the presence of females reduce foraging and focus on mating, while in the rest of the season these proportions are reversed.

Although the data concerning the changes of body condition of swarming populations is scarce, we observe that the Natterer's bat $\mathrm{BCI}$ changes pattern is consistent with other species taking part in this phenomenon. In Barbastella barbastellus during the period of the most intensive swarming activity, both adult females and adult males have the lowest BCI in season (Gottfried 2009). In M. daubentonii, the lowest body mass of adult males in swarming season overlaps with the swarming activity peak of adult females as well (Encarnação et al. 2004; Šuba et al. 2008; Rughetti and Toffoli 2014). Similarly, the short period of lowering the body mass of males of Plecotus auritus in autumn was interpreted as their mating effort (Entwistle et al. 1998). The compilation of results of studies relating to the swarming populations of $M$. daubentonii and M. mystacinus or Myotis brandtii indicates that adult males of these species seem to spend on foraging only the nights with low proportion of adult females (Piksa 2008; Šuba et al. 2008, 2011).

The BCI changes analyzed on the background of activity patterns of the latter three species indicate that for them the main period of fat accumulation occurs before the females' activity peak, i.e., before mating. Our results suggest that the Natterer's bat strategy is different.

\section{Late fat reserve buildup of adult males of the Natterer's bat in relation to foraging strategy}

In our study, the Natterer's bats appeared at the swarming site not earlier than late August. The adult males' seasonal and nightly $\mathrm{BCI}$ changes indicated that their fat accumulation for winter starts in October, after the species' peak of activity, and lasts nearly just before hibernation period. It was mentioned before that the peak of activity of the Natterer's bat occurs later in comparison to other swarming species such as: M. brandtii, M. mystacinus, M. daubentonii, Myotis dasycneme, and B. barbastellus (Furmankiewicz and Górniak 2002; Parsons et al. 2003; Piksa 2008; Šuba et al. 2008; Gottfried 2009). This late swarming activity was suggested to be coupled with the Natterer's bat's greatest gleaning ability (Parsons et al. 2003). British authors suggested, on the basis of results obtained by Barclay (1991), that gleaning could be beneficial during cold swarming nights in autumn. Indeed, diet of the Natterer's bat may consist of up to $70 \%$ of non-flying prey (Shiel et al. 1991; Andreas et al. 2012a). It was shown that for temperate bats of aerial hawkers, the food availability in October decreases to one quarter or even one tenth in comparison to its greatest abundance in July and August (Speakman and Rowland 1999). In fact, bats with the early swarming peak of activity forage mainly on flying prey (Flavin et al. 2001; Pithartová 2007; Lučan et al. 2009; Krüger et al. 2012; Andreas et al. 2012b; Nissen et al. 2013).

In the case of aerial hawkers and trawlers, the time for effective foraging in autumn seems to be shorter than for gleaners, and in consequence, the fat accumulation for those guilds starts earlier in the season, at flying prey activity peak. This regularity can be seen when comparing our results with the body mass seasonal changes of $M$. daubentonii adult males from the male colonies or loners (not swarming population) (Encarnação et al. 2004; Rughetti and Toffoli 2014). The body mass of $M$. daubentonii males is constantly growing from early August until early September, while our data shows that the Natterer's bat BCI starts to grow in late September achieving the highest value in late November, just before hibernation. Although M. daubentonii 
can use trawling (=gaffing) strategy which allows to collect prey from the water surface (Jones and Rayner 1988; Siemers et al. 2001), this feeding strategy has other constraints. It was observed that $M$. daubentonii activity time above the water is negatively affected by fog (Ciechanowski et al. 2007). In autumn, fog above the water bodies is more frequent than in summer. Thus, again, it seems to be more beneficial for trawling bats to accumulate most of their winter fat reserves earlier in the season. Our interpretation of differences in fat accumulation strategies between these guilds is reinforced by the latest surveys concerning the Natterer's bat and $M$. daubentonii. The energy budget balance in M. daubentonii shows that males of this species use combination of metabolic compensation and daily torpor in autumn to compensate for the low food availability, opposite to active food intake earlier in the season (Becker et al. 2013). In contrast, the Natterer's bat is able to forage effectively even in winter (Hope et al. 2014). Based on the results obtained in our work and cited literature data, we suggest that the Natterer's bat may simply postpone the active food intake (building fat reserves) in the swarming season to late autumn.

\section{Conclusions}

Our results revealed that adult females and subadults are mainly responsible for the swarming activity peak of the Natterer's bat (late September). Adult males visit the swarming site longer in the season than adult females, which supports the interpretation of this behavior as increasing the reproductive success of males (Rivers et al. 2006). The data collected in Skamieniałe Miasto Reserve showed that BCI values of adult males and adult females of the Natterer's bat were the lowest at the night of the species' activity peak and did not increase in consecutive hours of that night. Later in the season, when adult females were less numerous or absent (subadults only), the BCI value of adult males started to increase, both: in season and in night. It suggests that adult males of the Natterer's bat spend most of the night of their maximum swarming activity on mating, and postpone foraging and fat accumulation until after the mating. Our observation is in consent with an earlier premise regarding foraging strategies of temperate bats (Parsons et al. 2003; Becker et al. 2013): males of aerial hawkers and aerial hawker and trawler guilds have to build up most of their winter fat reserves before mating when the flying prey is more abundant, while gleaners as the Natterer's bat can postpone fat accumulation by active food intake even just before hibernation.

\footnotetext{
Acknowledgments We would like to thank students from the Student Naturalist Society of Jagiellonian University (KPStUJ) for actively participating in the surveys, Paweł Kozioł and Dagmara Klimczok from RDOŚ in Tarnów for their assistance in the field, and Wojciech Sanek from the Natural Science Museum in Ciężkowice for offering us accommodations. We are also grateful to Elżbieta Małkowska for help with the artwork.
}

Open Access This article is distributed under the terms of the Creative Commons Attribution 4.0 International License (http:// creativecommons.org/licenses/by/4.0/), which permits unrestricted use, distribution, and reproduction in any medium, provided you give appropriate credit to the original author(s) and the source, provide a link to the Creative Commons license, and indicate if changes were made.

\section{References}

Andreas M, Reiter A, Benda P (2012a) Dietary composition, resource partitioning and trophic niche overlap in three forest foliagegleaning bats in Central Europe. Acta Chiropterologica 14:335-345

Andreas M, Reiter A, Benda P (2012b) Prey selection and seasonal diet changes in the western barbastelle bat (Barbastella barbastellus). Acta Chiropterologica 14:81-92

Anthony ELP (1988) Age determination in bats. In: Kunz TH (ed) Ecol. Behav. methods study bats. Smithsonian Institution Press, Washington, D.C, pp 47-58

Barclay RMR (1991) Population structure of temperate zone insectivorous bats in relation to foraging behaviour and energy demand. J Anim Ecol 60:165-1781

Becker NI, Tschapka M, Kalko EKV, Encarnação JA (2013) Balancing the energy budget in free-ranging male Myotis daubentonii bats. Physiol Biochem Zool 86:361-369

Bogdanowicz W, Piksa K, Tereba A (2012) Hybridization hotspots at bat swarming sites. PLoS One 7:e53334

Ciechanowski M, Zając T, Biłas A, Dunajski R (2007) Spatiotemporal variation in activity of bat species differing in hunting tactics: effects of weather, moonlight, food abundance, and structural clutter. Can J Zool 85:1249-1263

Encarnação JA, Dietz M, Kierdorf U, Wolters V (2004) Body mass changes of male Daubenton's bats (Myotis daubentonii) during the seasonal activity period. Mammalia 68:291-297

Encarnação JA, Kierdorf U, Ekschmitt K, Wolters V (2006) Age-related variation in physical and reproductive condition of male Daubenton's bats (Myotis daubentonii). J Mammal 87:93-96

Entwistle AC, Racey PA, Speakman JR (1998) The reproductive cycle and determination of sexual maturity in male brown long-eared bats, Plecotus auritus (Chiroptera, Vespertilionidae). J Zool 244:63-70

Fenton MB (1969) Summer activity of Myotis lucifugus (Chiroptera: Vespertilionidae) at hibernacula in Ontario and Quebec. Can J Zool 47:597-602

Flavin DA, Biggane SS, Shiel CB et al (2001) Analysis of the diet of Daubenton's bat Myotis daubentonii in Ireland. Acta Theriol 46:43-52

Furmankiewicz J (2008) Population size, catchment area, and sexinfluenced differences in autumn and spring swarming of the brown long-eared bat (Plecotus auritus). Can J Zool 86:207-216

Furmankiewicz J, Altringham J (2007) Genetic structure in a swarming brown long-eared bat (Plecotus auritus) population: evidence for mating at swarming sites. Conserv Genet 8:913-923

Furmankiewicz J, Górniak J (2002) Seasonal changes in number and diversity of bat species (Chiroptera) in the Stolec mine (SW Poland). Przyr Sudetów Zachodnich Supl 2:49-70

Glover AM, Altringham JD (2008) Cave selection and use by swarming bat species. Biol Conserv 141:1493-1504

Gottfried I (2009) Use of underground hibernacula by the barbastelle (Barbastella barbastellus) outside the hibernation season. Acta Chiropterologica 11:363-373

Haarsma AJ (2008) Manual for assessment of reproductive status, age and health in European Vespertilionid bats, Electronic. Hillegom (Holland)

Hope PR, Bohmann K, Gilbert MTP et al (2014) Second generation sequencing and morphological faecal analysis reveal unexpected foraging 
behaviour by Myotis nattereri (Chiroptera, Vespertilionidae) in winter. Front Zool 11:39

Jonasson KA, Willis CKR (2011) Changes in body condition of hibernating bats support the thrifty female hypothesis and predict consequences for populations with white-nose syndrome. PLoS One.

Jones G, Rayner JMV (1988) Flight performance, foraging tactics and echolocation in free-living Daubenton's bats (Myotis daubentoni) (Chiroptera: Vespertilionidae). J Zool 215:113-132

Kerth G, Kiefer A, Trappmann C, Weishaar M (2003) High gene diversity at swarming sites suggest hot spots for gene flow in the endangered Bechstein's bat. Conserv Genet 4:491-499

Klassek G, Mleczek T (2014) Eksploracja i inwentaryzacja jaskiń polskich Karpat Fliszowych (wrzesień 2012 r. - sierpien 2014 r.). In: Stefaniak K, Ratajczak U, Wróblewski W (eds) Mater. 48. Symp. Speleol. Sekcja Speleologiczna Polskiego Towarzystwa Przyrodników im. Kopernika, Kraków, pp 76-80, 16-19.10.2014

Krüger F, Harms I, Fichtner A et al (2012) High trophic similarity in the sympatric North European trawling bat species Myotis daubentonii and Myotis dasycneme. Acta Chiropterologica 14:347-356

Kunz TH, Wrazen JA, Burnett CD (1998) Changes in body mass and fat reserves in pre-hibernating little brown bats (Myotis lucifugus). Ecoscience 5:8-17

Lučan RK, Andreas M, Benda P et al (2009) Alcathoe bat (Myotis alcathoe) in the Czech Republic: distributional status, roosting and feeding ecology. Acta Chiropterologica 11:61-69

Mleczek T (1997) Jaskinie Pogórza Ciężkowickiego. In: Pulina M (ed) Jaskinie Pol. Karpat Fliszowych. Tom 2. Jaskinie Beskidu Małego, Beskidu Makowskiego, Pogórza Wiśnickiego, Beskidu Wyspowego, Gorców, Beskidu Sądeckiego, Pogórza Rożnowskiego, Pogórza. PTPNoZ, Warszawa, pp 209-213

Nissen H, Krüger F, Fichtner A, Sommer RS (2013) Local variability in the diet of Daubenton's bat (Myotis daubentonii) in a lake landscape of Northern Germany. Folia Zool 62:36-41

Parsons KN, Jones G, Davidson-Watts I, Greenaway F (2003) Swarming of bats at underground sites in Britain-implications for conservation. Biol Conserv 111:63-70

Piksa K (2008) Swarming of Myotis mystacinus and other bat species at high elevation in the Tatra Mountains, southern Poland. Acta Chiropterologica 10:69-79
Piksa K, Bogdanowicz W, Tereba A (2011) Swarming of bats at different elevations in the Carpathian Mountains. Acta Chiropterologica 13: $113-122$

Pithartová T (2007) Potravní ekologie syntopických populací čtyř druhů netopýrů (Myotis daubentonii, Myotis mystacinus, Pipistrellus nathusii, Pipistrellus pygmaeus): struktura potravy a její sezónní dynamika. Vespertilio 11:119-165

Racey PA (1974) Ageing and assessment of reproductive status of pipistrelle bats, Pipistrellus pipistrellus. J Zool London 173:264-271

Rivers NM, Butlin RK, Altringham JD (2005) Genetic population structure of Natterer's bats explained by mating at swarming sites and philopatry. Mol Ecol 14:4299-4312

Rivers NM, Butlin RK, Altringham JD (2006) Autumn swarming behaviour of Natterer's bats in the UK: population size, catchment area and dispersal. Biol Conserv 127:215-226

Rughetti M, Toffoli R (2014) Sex-specific seasonal change in body mass in two species of vespertilionid bats. Acta Chiropterologica 16:149-155

Schick P, Łupicki D, Cichocki J, Telatyński S (2003) Oszacowanie wieku nocka dużego $M$. myotis na podstawie stopnia zużycia kłów. Nietoperze IV:93-100

Shiel CB, McAney CM, Fairley JS (1991) Analysis of the diet of Natterer's bat Myotis nattereri and the common long-eared bat Plecotus auritus in the West of Ireland. J Zool 223:299-305

Siemers BM, Stilz P, Schnitzler HU (2001) The acoustic advantage of hunting at low heights above water: behavioural experiments on the European "trawling" bats Myotis capaccinii, M. dasycneme and $M$. daubentonii. J Exp Biol 204:3843-3854

Speakman JR, Racey PA (1986) The influence of body condition on sexual development of male brown long-eared bats (Plecotus auritus) in the wild. J Zool London 210:515-525

Speakman JR, Rowland A (1999) Preparing for inactivity: how insectivorous bats deposit a fat store for hibernation. Proc Nutr Soc 58:123-131

Šuba J, Vintulis V, Pētersons G (2008) Late summer and autumn swarming of bats at Sikspārnu caves in Gauja National Park. Acta Univ Latv 745:43-52

Šuba J, Vintulis V, Pētersons G (2011) Body weight provides insight into the feeding strategy of swarming bats. Hystrix It J Mamm 22:179-187

Trappmann C (1997) Aktivitätsmuster einheimischer Fledermäuse an einem bedeutenden Winterquartier in den Baumbergen. Abh Westf Mus Naturkd 59:51-62 